\title{
Detection of Non-Typhoidal Salmonella Using a Mechanism for Controlling Hydrogen Sulfide Production
}

\author{
Yutaka Midorikawa ${ }^{1}$, Satoshi Nakamura ${ }^{2}$, Rattanaphone Phetsouvanh ${ }^{3}$, \\ Kaoru Midorikawa ${ }^{4}$ \\ ${ }^{1}$ Suzuka University of Medical Science, Suzuka, Japan \\ ${ }^{2}$ Research Institute of National Center for Global Health and Medicine, Tokyo, Japan \\ ${ }^{3}$ Wellcome Trust-Mahosot Hospital, Oxford University Tropical Medicine Research Collaboration, Vientiane, \\ Laos \\ ${ }^{4}$ Department of Hygiene, School of Medicine, Mie University, Tsu, Japan \\ Email: midorika@suzuka-u.ac.jp
}

Received 14 January 2014; revised 14 February 2014; accepted 21 February 2014

Copyright (C) 2014 by authors and Scientific Research Publishing Inc.

This work is licensed under the Creative Commons Attribution International License (CC BY).

http://creativecommons.org/licenses/by/4.0/

(c) (i) Open Access

\section{Abstract}

To know the relation between $\mathrm{NaCl}$ concentration and hydrogen sulfide $\left(\mathrm{H}_{2} \mathrm{~S}\right)$ production by $\mathrm{MY}$ Phenomenon of Salmonella, we developed a method to control $\mathrm{H}_{2} \mathrm{~S}$ production by Salmonella in this study. Desoxycholate-hydrogen sulfide-lactose (DHL) agar was used as the selective medium for Salmonella. Triple sugar iron (TSI) agar was used as the screening medium. Citric acid disks were placed on DHL agar. $\mathrm{NaCl}$ was added to both media. After 24 hours incubation, $\mathrm{H}_{2} \mathrm{~S}$ production on DHL agar was stimulated by citric acid, whereas production was suppressed by adding $\mathrm{NaCl}$. The color change in the bottom of the TSI medium was due to the low production of black FeS. The production of FeS was reduced by lower $\mathrm{H}_{2} \mathrm{~S}$ production by Salmonella with an increasing concentration of $\mathrm{NaCl}$ from $0.5 \%$ to $3 \%$. The inhibition of the black color meant that the color change due to glucose fermentation could be seen clearly in the bottom of the agar. The current method cannot detect glucose fermentation but the addition of more $\mathrm{NaCl}$ to the TSI medium allowed the visualization of glucose fermentation by Salmonella. Although $\mathrm{H}_{2} \mathrm{~S}$ production of salmonella was promoted by citrate etc., being controlled by sodium chloride was proved in this study. Thus, we had developed a possibility of novel technique for the detection of Salmonella etc.

\section{Keywords}

Salmonella; $\mathrm{H}_{2} \mathrm{~S}$; MY Phenomenon; MIDO Ring; NaCl 


\section{Introduction}

Nontyphoidal Salmonella is a bacterial infection that can be harmful to the intestines. These infections are zoonotic in origin and can be transferred between humans and animals [1]. Salmonella is one of the most commonly detected bacteria in retail meats and food animals, and it ranks second among bacteria-associated human infections, causing an estimated 2500 annual cases in Japan [2]. Infections usually occur as a result of the foods that Salmonella have multiplied in, which are highly concentrated in a form similar to a culture medium [3]. Most people infected with Salmonella develop diarrhea, fever, vomiting, and abdominal cramps 12 - $72 \mathrm{~h}$ after infection [4]. A definitive diagnosis usually requires bacterial isolation and identification using various techniques. PCR tests have also been used to distinguish bacterial strains recently [5] [6]. However, traditional methods are generally used [7]. Traditional methods for the diagnosis of Salmonella strains include culture on selective media, which is followed by biochemical and serological identification tests. These approaches have been used successfully in clinical diagnostic laboratories and epidemiological surveillance [8]. Organisms that produce hydrogen sulfide $\left(\mathrm{H}_{2} \mathrm{~S}\right)$ via the reduction of thiosulfate are easily detected. $\mathrm{H}_{2} \mathrm{~S}$ reacts with iron in the medium to produce iron sulfide (FeS) as a black precipitate. Citrus fruits and their extracts affect the production of $\mathrm{H}_{2} \mathrm{~S}$ by Salmonella and this facilitated our development of a simple new method for detecting Salmonella [9]. Salmonella forms a black ring due to the production of $\mathrm{H}_{2} \mathrm{~S}$ on desoxycholate-hydrogen sulfide-lactose (DHL) agar, where the selective medium was put with citrus fruits and their extracts. We referred to this phenomenon as the "Midorikawa Yutaka (MY) Phenomenon" and the black ring was designated as the MIDO Ring [10]. In the current study, we found that $\mathrm{NaCl}$ could control $\mathrm{H}_{2} \mathrm{~S}$ production by Salmonella. We used triple sugar iron (TSI) agar to determine whether bacteria could ferment glucose and/or lactose and whether they produced $\mathrm{H}_{2} \mathrm{~S}$ or other gases. If an organism can ferment glucose, it is designated as "glucose positive." If it can ferment lactose, it is designated as "lactose positive." The TSI medium also tests for the ability to ferment sucrose. These characteristics can help to distinguish various Enterobacteriacae including Salmonella and Shigella, which are intestinal pathogens [11]. TSI medium contained three sugars: glucose, lactose, and sucrose. Lactose and sucrose are present at 10 times the concentration of glucose (1.0\% versus $0.1 \%$ ). Ferrous sulfate, phenol red (a pH indicator, which is yellow below pH 6.8 and red above it), and nutrient agar were also present. The slant tube was inoculated by stabbing into the agar bottom (bottom of the tube) using an inoculating wire and streaking the slant in a wavy pattern. The results were read after 18 - $24 \mathrm{~h}$ of incubation. If an organism only fermented glucose, the entire tube turns yellow due to the effect of the acid produced on phenol red. The tube contains a minimal amount of glucose in so the organism quickly exhausts it and begins oxidizing amino acids for energy. Thus, ammonia is produced and the $\mathrm{pH}$ is increased. Within $24 \mathrm{~h}$, the phenol red indicator reverted to its original red color in the slant. The TSI medium was poured as a deep slant so the bottom had limited oxygen supply and the bacteria were unable to oxidize amino acids in that region. Thus, the bottom remained yellow. Therefore, a TSI slant medium containing Salmonella should turn red, whereas the bottom of the slant should turn yellow. If $\mathrm{H}_{2} \mathrm{~S}$ is produced, it reacts with ferrous sulfate (III) and a black precipitate of ferric sulfide FeS (II) is formed in the bottom of the tube. Organism that produces large amounts of $\mathrm{H}_{2} \mathrm{~S}$ (e.g., Salmonella and Proteus) as a black precipitate may mask the yellow (acid) color in the bottom of the tube, thus making use of TSI agar to detect Salmonella problematic. In this study, we developed a method to overcome this problem.

\section{Materials and Methods}

\subsection{Bacteria and Reagents}

Eight bacterial strains of nontyphoidal Salmonella (Salmonella enterica subsp. enterica serovar Derby, London, Anatum, Rissen, Hvittingfoss, Brunei, Kedouguou, Potengi) isolated from markets or hospitals in Lao P.D.R. in Southeast Asiawas used in this experiment [12]. The serotype was designated according to the KauffmannWhite scheme. DHL agar and TSI agar (Eiken Kagaku, Japan) were used as the basal media for Salmonella culture. A serotype Typhi was also used. Citric acid and $\mathrm{NaCl}$ (Nakalai Tesque, Japan) were added to the basal media.

\subsection{Formation of an MIDO Ring in DHL Agar}

The Salmonella strain was pre-cultured for $24 \mathrm{~h}$ on DHL agar or TSI agar. The bacteria were sampled from the surfaces of these culture media using a swab. The swab was used to inoculate the surface of the DHL medium. 
Two separate agar plates were prepared in Petri dishes. One medium did not include $\mathrm{NaCl}$ whereas the other medium contained $2 \% \mathrm{NaCl}$ solution. A circular filter paper (Advantec Toyo, Japan) measuring $10 \mathrm{~mm}$ that contained $20 \mathrm{mg}$ citrate acid was placed in the center of each DHL agar plate. After $24 \mathrm{~h}$ incubation, MIDO Ring formation by Salmonella was observed visually.

\subsection{Effect of Adding $\mathrm{NaCl}$ to TSI Medium on $\mathrm{H}_{2} \mathrm{~S}$ Production by Salmonella}

The Salmonella strains were inoculated onto TSI agar, which already contained $0.5 \% \mathrm{NaCl}$. The $\mathrm{NaCl}$ content was increased gradually from $0.5 \%$ by adding $\mathrm{NaCl}$, i.e., agars containing $0.5 \%, 1.0 \%, 1.5 \%, 2.0 \%, 2.5 \%, 3.0 \%$, $3.5 \%, 4.0 \%, 4.5 \%, 5.0 \%, 5.5 \%$ or $6.0 \%$ (wt/vol) were produced, as appropriate. The total number of TSI agar tubes was 12. Next the Salmonella strains were inoculated into each TSI tube, which was incubated at $37^{\circ} \mathrm{C}$ for $24 \mathrm{~h}$. We observed changes in the color of the TSI medium, $\mathrm{H}_{2} \mathrm{~S}$ production, and the growth of Salmonella. The survivals of Salmonella were tested by inoculating another TSI agar for comparison.

\section{Results}

\subsection{Effect of $\mathrm{NaCl}$ on Mido Ring Formation DHL without $\mathrm{NaCl}$}

Salmonella produced $\mathrm{H}_{2} \mathrm{~S}$ and the iron (III) in the DHL medium was reduced by the $\mathrm{H}_{2} \mathrm{~S}$. The reduced iron (II) formed a black ring (MIDO Ring) on the surface of the agar. Citric acid stimulated $\mathrm{H}_{2} \mathrm{~S}$ of Salmonella. Thus, the MY phenomenon was observed in the DHL medium. The same results were obtained with all the serum types of non typhoid Salmonella used in this study. However, the serotype Typhi strain did not form the ring (Table 1).

\subsection{DHL Agar Containing $2 \% \mathrm{NaCl}$}

Salmonella was cultured and a black ring was not produced in the agar containing $2 \% \mathrm{NaCl}$. Thus, the MY phenomenon did not occur in the presence of $\mathrm{NaCl}$ (Figure 1). $\mathrm{H}_{2} \mathrm{~S}$ production of salmonella was controlled by increasing the $\mathrm{NaCl}$ concentration of medium. The same results were obtained with all the serum types of Salmonella used in this study.

\subsection{Effect of $\mathrm{NaCl}$ Addition to TSI Agar on $\mathrm{H}_{2} \mathrm{~S}$ Production by Salmonella}

With $0.5 \%-2.5 \% \mathrm{NaCl}$ in the TSI medium, the $\mathrm{H}_{2} \mathrm{~S}$ production by Salmonella was no change (Figure 2). $\mathrm{H}_{2} \mathrm{~S}$ production was suppressed with $3 \% \mathrm{NaCl}$. The black portion decreased in size with the increase in the $\mathrm{NaCl}$ concentration. It was possible to see the color change in the bottom of the TSI test tube because the black por-

Table 1. Formation of MIDO Ring on DHL Medium by Salmonella Sero type Derby, London, Anatum, Rissen, Hvittingfoss, Brunei, Kedouguou, Potengi, Typhi.

\begin{tabular}{|c|c|c|c|c|c|c|c|c|c|c|}
\hline $\mathrm{NaCl}$ & Sero type & Derby & London & Anatum & Rissen & Hvittingfoss & Brunei & Kedouguou & Potengi & Typhi \\
\hline $0 \%$ & $\begin{array}{l}\text { Mido } \\
\text { Ring }\end{array}$ & $\bullet$ & $\bullet$ & $\bullet$ & $\bullet$ & $\bullet$ & $\bullet$ & $\bullet$ & $\bullet$ & $\bullet$ \\
\hline $2 \%$ & $\begin{array}{l}\text { Mido } \\
\text { Ring }\end{array}$ & $\times$ & $\times$ & $x$ & $x$ & $x$ & $\times$ & $x$ & $x$ & $x$ \\
\hline
\end{tabular}

•Formatiion of Mido ring; $\times$ None formation of Mido ring.
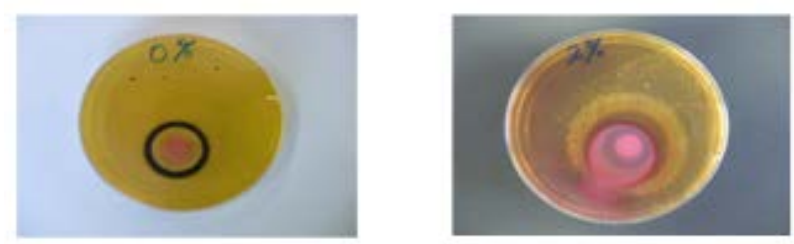

Figure 1. The plate on the left is DHL agar without $\mathrm{NaCl}$. The plate on the right is DHL agar with $2 \% \mathrm{NaCl}$. 
tion was smaller. The black portion was absent from the lower part of the TSI agar test tube when the $\mathrm{NaCl}$ concentration was $4.5 \%$. Thus, Salmonella grew at this concentration but without $\mathrm{H}_{2} \mathrm{~S}$ production. However, $\mathrm{H}_{2} \mathrm{~S}$ production and the growth of Salmonella were totally inhibited when the $\mathrm{NaCl}$ concentration was $6 \%$ (Table 2). Same result in all of non typoid Salmonella in this experiment was obtained.

\section{Discussion}

The identification of non-typhoidal Salmonella based onhydrogen sulfide $\left(\mathrm{H}_{2} \mathrm{~S}\right)$ production is one of important methods. Salmonella strains that lack $\mathrm{H}_{2} \mathrm{~S}$ production are rarely isolated. Laboratory technicians must be aware of how to control $\mathrm{H}_{2} \mathrm{~S}$ production. Rapid tests such as the polymerase chain reaction (PCR) can be used to detect the genetic material of bacteria, but PCR is not sufficiently sensitive to detect organisms in feces [13]. "Positive by PCR" means only "It was detected as a gene". For example, though the gene for toxin was isolated, bacterial toxins and it have not been detected.

The definitive diagnosis of Salmonella infections is based on the culture of the organisms isolated from a patient or occasionally from an infection source (e.g., food or water). In most cases, the samples are cultured on agar media that are selective for Salmonella spp. DHL agar is one of best-known media used for selecting Salmonella.

Salmonella detection in stools using conventional media such as DHL is based on lactose fermentation and $\mathrm{H}_{2} \mathrm{~S}$ production. The number of false positive results with these media necessitates time-consuming and expensive additional testing. Thus, the Mido Ring produced by the MY phenomenon was developed to ensure greater specificity during the isolation of Salmonella.

The formation of a MIDO Ring on DHL medium is due to $\mathrm{H}_{2} \mathrm{~S}$ production by Salmonella in the presence of citric acid. The iron citrate in DHL medium is reduced to $\mathrm{FeS}$ by $\mathrm{H}_{2} \mathrm{~S}$ and the color changes from red to black.

However, the MIDO Ring was not formed in DHL medium containing $2 \% \mathrm{NaCl}$, which showed that the MY phenomenon was absent with higher $\mathrm{NaCl}$ concentrations. Clearly, $\mathrm{NaCl}$ prevented $\mathrm{H}_{2} \mathrm{~S}$ production by Salmonella. In DHL medium, the $2 \% \mathrm{NaCl}$ solution was the point where Salmonella growth was possible whereas $\mathrm{H}_{2} \mathrm{~S}$ production was prevented.

In the TSI medium, however, FeS formation due to $\mathrm{H}_{2} \mathrm{~S}$ production started to be suppressed with $3 \% \mathrm{NaCl}$ and $\mathrm{H}_{2} \mathrm{~S}$ production was totally absent with $4.5 \% \mathrm{NaCl}$. This showed that additional $\mathrm{NaCl}$ suppressed $\mathrm{H}_{2} \mathrm{~S}$ production by Salmonella in the medium. However, the growth of Salmonella was possible with $5.5 \% \mathrm{NaCl}$, al-

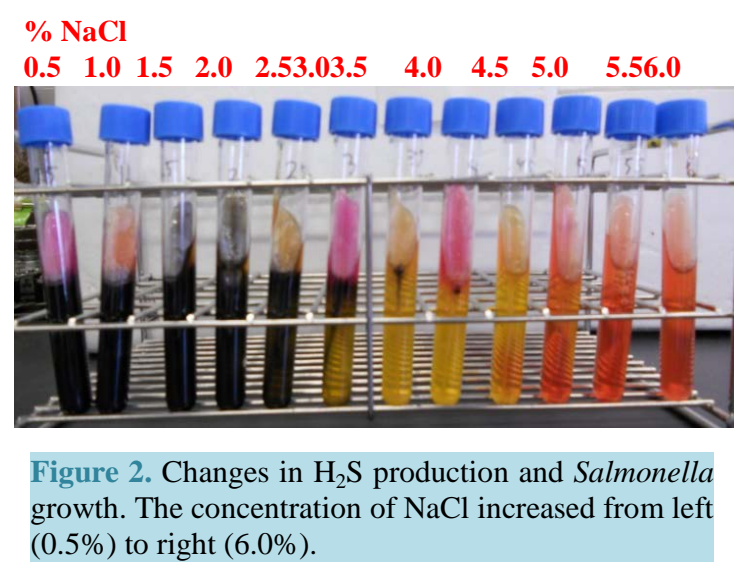

Table 2. Effects of the $\mathrm{NaCl}$ concentration on $\mathrm{H}_{2} \mathrm{~S}$ production, etc.

\begin{tabular}{|c|c|c|c|c|c|c|c|c|c|c|c|c|}
\hline $\mathrm{NaCl} \%$ in TSI & 0.5 & 1 & 1.5 & 2 & 2.5 & 3 & 3.5 & 4 & 4.5 & 5 & 5.5 & 6 \\
\hline $\mathrm{H}_{2} \mathrm{~S}$ production & $\bullet$ & $\bullet$ & $\bullet$ & $\bullet$ & $\bullet$ & $\bullet$ & $\bullet$ & $\bullet$ & 。 & 。 & 。 & 。 \\
\hline Color in the bottom of the tube & Black & Black & Black & Black & Black & Yellow & Yellow & Yellow & Red & Red & Red & Red \\
\hline Salmonella growth & Grow & Grow & Grow & Grow & Grow & Grow & Grow & Grow & Grow & Grow & Grow & No grow \\
\hline
\end{tabular}

$\bullet \mathrm{H}_{2} \mathrm{~S}$ produced; ${ }^{\circ} \mathrm{H}_{2} \mathrm{~S}$ not produced. 


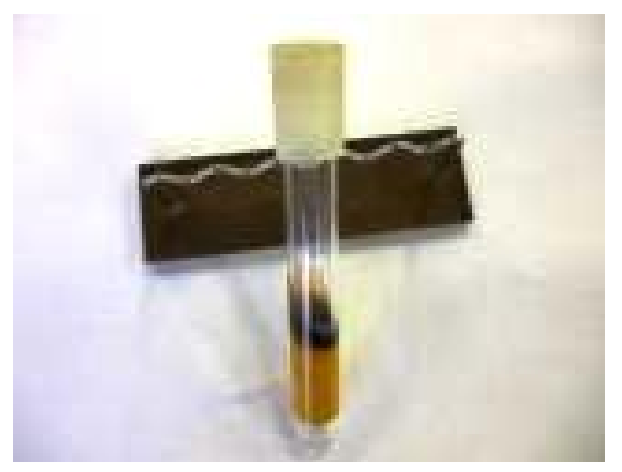

Figure 3. TSI agar containing $3 \% \mathrm{NaCl}$ after $24 \mathrm{~h}$ incubation with Salmonella.

though Salmonella growth stopped in the presence of $6 \% \mathrm{NaCl}$. Thus, the $\mathrm{H}_{2} \mathrm{~S}$ production was suppressed before the growth of Salmonella was prevented.

With $3 \% \mathrm{NaCl}$, there was less of the black iron sulfide precipitate so the color change could be seen in the bottom part of the agar (i.e., yellow). Thus, glucose fermentation by Salmonella was detected. The addition of $\mathrm{NaCl}$ allowed the visualization of glucose fermentation by Salmonella. Previously, the color change could not be distinguished because too much black FeS was produced by $\mathrm{H}_{2} \mathrm{~S}$.

The bottom part of the TSI medium had a yellow color due to glucose fermentation, but it was usually black because of $\mathrm{H}_{2} \mathrm{~S}$ production. Thus, the conventional method using $0.5 \% \mathrm{NaCl}$ prevented the observation of glucose fermentation. However, it is well documented that $\mathrm{H}_{2} \mathrm{~S}$ production in TSI requires an acidic environment so fermentation is inferred when the butt is black. With $3 \% \mathrm{NaCl}$ in the TSI, the glucose fermentation due to Salmonella could be seen with the naked eye (Figure 3).

Further studies are required to evaluate the MY phenomenon in many more bacterial species that produce $\mathrm{H}_{2} \mathrm{~S}$. However, Genotyping methods have been developed for genetic discrimination of Salmonella isolates in outbreaks [14]. [16].

This method could be put to practical use in countries where the risk of Salmonella infections is high [15]

\section{Acknowledgements}

This study was supported by JSPS KAKENHI Grand Number 18650222, 22500783.The authors would like to thank Enago (www.enago.jp) for the English language review.

\section{References}

[1] Stevens, M.P., Humphrey, T.J. and Maskell, D.J. (2009) Molecular Insights into Farm Animal and Zoonotic Salmonella Infections. Philosophical Transactions of the Royal Society B Biological Sciences, 27, 2709-2723. http://dx.doi.org/10.1098/rstb.2009.0093

[2] Herikstad, H., Motarjemi, Y. and Tauxe, R.V. (2002) Salmonella Surveillance: A Global Survey of Public Health Serotyping. Epidemioly and Infection, 129, 1-8. http://dx.doi.org/10.1017/S0950268802006842

[3] Centers for Disease Control and Prevention (2008) Salmonella: Annual Summary, 2006. U.S. Department of Health and Human Services, CDC, Atlanta. http://www.cdc.gov/ncidod/dbmd/phlisdata/salmtab/2006/SalmonellaAnnualSummary

[4] Coburn, B., Grassl, G.A. and Finlay, B.B. (2007) Salmonella, the Host and Disease: A Brief Review. Immunology and Cell Biology, 85, 112-118. http://dx.doi.org/10.1038/sj.icb.7100007

[5] Bhatta, D.R., Bangtrakulnonth, A., Tishyadhigama, P., Saroj, S.D., Bandekar, J.R., Hendriksen, R.S. and Kapadnis, B.P. (2007) Serotyping, PCR, Phage-Typing and Antibiotic Sensitivity Testing of Salmonella Serovars Isolated from Urban Drinking Water Supply Systems of Nepal. Letter in Appllied Microbiology, 44, 588-594. http://dx.doi.org/10.1111/j.1472-765X.2007.02133.x

[6] Wise, M.G., Siragusa, G.R., Plumblee, J., Healy, M., Cray, P.J. and Seal, B.S. (2009) Predicting Salmonella enterica Serotypes by Repetitive Sequence-Based PCR. Journal of Microbiological Methods, 76, 18-24.

[7] Bale, J.A., Pinna de, E., Threlfall, E.J. and Ward, L.R. (2007) Kauffmann-White Scheme 2007: Salmonella Identifica- 
tion; Serotypes and Antigenic Formulae. Centre for Infections, Health Protection Agency, London.

[8] Grimont, P.A.D. and Weill, F.X. (2007) Antigenic Formulae of the Salmonella Serovars. 9th Edition, World Health Organization Collaborating Center for Reference and Research on Salmonella, Institut Pasteur, Paris.

[9] Midorikawa, Y., Nakamura, S., Newton, P., Phetsouvanh, R. and Midorikawa, K. (2009) A Phenomenon for Detect Salmonella Using Device from Citrus Extracts. Tropical Medicine and Health, 37, 115-120. http://dx.doi.org/10.2149/tmh.2008-29

[10] Midorikawa, Y., Nakamura, S., Phetsouvanh, R., Vongsouvaht, M. and Midorikawa, K. (2010) Detection of Non-Typhoid Salmonella Infection by Citrus and Citrus Extracts in Lao PDR. Asian Pacific Journal of Tropical Medicine, 3, 939-942. http://dx.doi.org/10.1016/S1995-7645(11)60004-7

[11] Ma, M., Amano, T., Enokimoto, M., Yano, T., Moe, K.K. and Misawa, N. (2007) Influence of pH of TSI Medium on the Detection of Hydrogen Sulfide Production by Campylobacter hyointestinalis. Letter in Applied Microbiology, 44, 544-549. http://dx.doi.org/10.1111/j.1472-765X.2006.02097.X

[12] Midorikawa, Y., Nakamura, S., Iwade, Y., Sugiyama, A., Sisavath, L. and Phakhounthong, R. (1996) Bacterial Diarrhea in Laos, a Region Where Cholerae Was Endemic. The Southeast Asian Journal of Tropical Medicine and Public Health, 27, 724-727.

[13] Malorny, B. and Hoorfar, J. (2005) Toward Standardization of Diagnostic PCR Testing of Fecal Samples: Lessons from the Detection of Salmonellae in Pigs. Journal of Clinical Microbiology, 43, 3033-3037. http://dx.doi.org/10.1128/JCM.43.7.3033-3037.2005

[14] Wonderling, L., Pearce, R., Wallace, F.M., Call, J. E., Feder, I., Tamplin, M. and Luchansky, J.B. (2003) Use of Pulsed-Field Gel Electrophoresis to Characterize the Heterogeneity and Clonality of Salmonella Isolates Obtained from the Carcasses and Feces of Swine at Slaughter. Applied and Environmental Microbiology, 69, 4177-4182.

[15] Washio, J., Sato, T., Koseki, T. and Takahashi, N. (2005) Hydrogen Sulfide-Producing Bacteria in Tongue Biofilm and Their Relationship with Oral Malodour. Journal of Medical Microbiology, 54, 889-895. http://dx.doi.org/10.1099/jmm.0.46118-0

[16] Vandenberg, O., Nyarukweba, D.Z., Ndeba, P.M., Hendriksen, R.S., Barzilay, E.J., Schirvel, C., Bisimwa, B.B., Collard, J.M., Aidra Kane, A. and Aarestrup, F.M. (2010) Microbiologic and Clinical Features of Salmonella Species Isolated from Bacteremic Children in Eastern Democratic Republic of Congo. Pediatric Infectious Disease Journal, 29, 504-510. http://dx.doi.org/10.1097/INF.0b013e3181cd615a 